\title{
O CONCEITO DE CAPACIDADE LEGAL NA CONVENÇÃO SOBRE OS DIREITOS DAS PESSOAS COM DEFICIÊNCIA
}

\author{
THE CONCEPT OF LEGAL CAPACITY IN THE CONVENTION ON THE RIGHTS \\ OF PERSONS WITH DISABILITIES
}

\section{EL CONCEPTO DE CAPACIDAD LEGAL EN LA CONVENCIÓN SOBRE LOS DERECHOS DE LAS PERSONAS COM DISCAPACIDAD}

\author{
FABIO QUEIROZ PEREIRA \\ https: / /orcid.org/0000-0002-3122-8759 / http://lattes.cnpq.br/1269002058299731 / fabioqueiroz@ufmg.br \\ Universidade Federal de Minas Gerais \\ Belo Horizonte, Minas Gerais, Brasil.
}

\begin{abstract}
MARIANA ALVES LARA
http://orcid.org/0000-0002-8580-3405 / http:// lattes.cnpq.br/6691591501135325 / mariana@mcampos.br Faculdade de Direito Milton Campos Belo Horizonte, Minas Gerais, Brasil.
\end{abstract}

DANIEL DE PÁDUA ANDRADE https://orcid.org/0000-0002-5513-4650 / http:/ / lattes.cnpq.br/0340717790892184 / danieldepaduaandrade@gmail.com Universidade Federal de Minas Gerais Belo Horizonte, Minas Gerais, Brasil

\section{RESUMO}

O trabalho busca analisar o alcance da expressão “capacidade legal” prevista pelo art. 12 da Convenção sobre os Direitos das Pessoas com Deficiência, como direito a ser exercido em igualdade de condições com relação às demais pessoas. A partir de um estudo em consonância com os direitos humanos e os princípios de Direito Internacional, é problematizada a interpretação estabelecida pelo Comitê sobre os Direitos das Pessoas com Deficiência na Orientação Geral $n^{\circ}$ 1. Conclui-se pelo afastamento da compreensão de capacidade legal como capacidade de exercício, pugnando por um enquadramento atento ao discernimento, às potencialidades e limitações das pessoas com deficiência mental.

Palavras-chave: Capacidade de Exercício; Capacidade Legal; Convenção sobre os Direitos das Pessoas com Deficiência; Direitos Humanos; Interpretação de Tratados.

\begin{abstract}
This paper aims to analyze the meaning of the expression "legal capacity" provided by article 12 of the Convention on the Rights of Persons with Disabilities as a right to be exercised on an equal basis with others. Based on a study in line with human rights and the principles of international law, the interpretation established by the Committee on the Rights of Persons with Disabilities in General Comment $\mathrm{n}^{\circ} 1$ is problematized. The conclusion is that the understanding of legal capacity as capacity of exercise must be abandoned, in order to pursuit a framework that focuses on the discernment, the potentialities and limitations of persons with mental disabilities.
\end{abstract}

Keywords: Capacity of Exercise; Legal Capacity; Convention on the Rights of Persons with Disabilities; Human Rights; Interpretation of Treaties 


\section{RESUMEN}

El trabajo busca analizar el alcance de la expresión "capacidad legal" prevista por el art. 12 de la Convención sobre los Derechos de las Personas con Discapacidad como derecho a ser ejercido en igualdad de condiciones con las demás personas. A partir de un estudio en consonancia con los derechos humanos y los principios de derecho internacional, es problematizada la interpretación establecida por el Comité sobre los Derechos de las Personas con Discapacidad en la Observación General $n^{\circ}$ 1. Se concluye por el alejamiento de la comprensión de capacidad legal como capacidad de ejercicio, pugnando por un encuadramiento atento al discernimiento, a las potencialidades y limitaciones de las personas con deficiencia mental.

Palabras clave: Capacidad del Ejercicio; Capacidad Legal; Convención sobre los Derechos de las Personas con Discapacidad; Derechos Humanos; Interpretación de Tratados.

\section{SUMÁRIO}

INTRODUÇAO; 1 CONVENÇÃO SOBRE OS DIREITOS DAS PESSOAS COM DEFICIÊNCIA E CAPACIDADE LEGAL; 2 CAPACIDADE DE EXERCÍCIO E DIREITOS HUMANOS; 3 A ATUAÇÃO DO COMITÊ SOBRE OS DIREITOS DAS PESSOAS COM DEFICIÊNCIA NA INTERPRETAÇÃO DOS TERMOS DA CONVENÇÃO; CONCLUSÃO; REFERÊNCIAS.

\section{INTRODUÇÃO}

Em 30 de março de 2007, foram assinados na Assembleia das Nações Unidas em Nova lorque a Convenção sobre os Direitos das Pessoas com Deficiência e seu Protocolo Facultativo, que consistem em importantes instrumentos legais de promoção e proteção dos direitos humanos das pessoas com deficiência. ${ }^{1}$

A Convenção adota um conceito social de deficiência, afastando-se de noções puramente médicas ou funcionais. No artigo 1, define pessoas com deficiência como "aquelas que têm impedimentos de longo prazo de natureza física, mental, intelectual ou sensorial, os quais, em interação com diversas barreiras, podem obstruir sua participação plena e efetiva na sociedade em igualdades de condições com as demais pessoas". Trata-se de um conceito bastante amplo, que prescinde de um rol enumerativo dos tipos de deficiência e abarca tanto as limitações físicas como as mentais ou intelectuais.

A partir dessa definição, a Convenção estabelece como seu propósito, também no artigo 1, "promover, proteger e assegurar o exercício pleno e equitativo de todos os direitos humanos e liberdades fundamentais por todas as pessoas com deficiência e promover o respeito pela sua dignidade inerente". Trata-se de um instrumento que busca estimular os Estados Partes a

\footnotetext{
${ }^{1}$ O Brasil foi signatário da Convenção sobre os Direitos das Pessoas com Deficiência e a recepcionou com status de emenda constitucional, após aprovação pelo Congresso Nacional, por meio do Decreto Legislativo $\mathrm{n}^{\circ} 186$, de 9 de julho de 2008 , seguindo o procedimento fixado no art. $5^{\circ}$, $\S 3^{\circ}$, da Constituição da República. A referida Convenção foi internalizada no ordenamento brasileiro pelo Decreto $\mathrm{n}^{\circ} 6.949$, de 25 de agosto de 2009.
} 
adotarem medidas de inclusão das pessoas com deficiência na sociedade e de respeito aos seus direitos humanos.

Dentre os direitos positivados na Convenção, tem suscitado intensos debates o denominado "reconhecimento igual perante a lei", disposto no artigo 12. Esse artigo prevê que "as pessoas com deficiência têm o direito de ser reconhecidas em qualquer lugar como pessoas perante a lei" e que "os Estados Partes reconhecerão que as pessoas com deficiência gozam de capacidade legal em igualdade de condições com as demais pessoas em todos os aspectos da vida".

As discussões acerca da capacidade das pessoas com deficiência centram-se, sobretudo, no alcance da expressão “capacidade legal” e nas consequências desse alcance para a efetiva proteção dos sujeitos no que se refere ao exercício dos atos da vida civil. O Comitê sobre os Direitos das Pessoas com Deficiência, criado pela Convenção, sugere que o termo capacidade legal abrange as noções de capacidade de direito e de exercício. A partir dessa determinação, o presente trabalho investiga se a capacidade de exercício é um direito humano, ou se, para atingir a igualdade material, o ideal seria empreender uma análise individualizada das diversas situações concretas, com a possibilidade de supressão da capacidade de agir quando o sujeito for totalmente privado do discernimento.

Por meio de uma pesquisa de vertente jurídico-dogmática, de tipo compreensivopropositivo, em que predomina a utilização do raciocínio indutivo-dedutivo e a análise de fontes diretas primárias, busca-se demonstrar a incorreção da leitura extremada do termo "capacidade legal” previsto no artigo 12 da Convenção. O reconhecimento de plena capacidade de exercício para as pessoas com deficiência não deve ser interpretado como imperativo absoluto e inafastável, mas sim como regra geral passível de ser excepcionada em situações devidamente fundamentadas e orientadas para a proteção de sujeitos que demandem cuidados jurídicos especiais.

Nesse desiderato, o capítulo 1 evidencia a interface entre a proteção da "capacidade legal” das pessoas com deficiência trazida pelo artigo 12 da Convenção e a teoria das incapacidades desenvolvida no ordenamento jurídico brasileiro. Em seguida, o capítulo 2 contextualiza o tema-problema no âmbito das tendências contemporâneas do Direito Internacional dos Direitos Humanos, que envolvem o paradigma da igualdade material e a busca pela proteção concreta dos integrantes de grupos vulneráveis, referenciais teóricos adotados neste trabalho. Já o capítulo 3 apresenta uma série de argumentos hermenêuticos para afastar a 
interpretação da expressão “capacidade legal” oficializada pelo Comitê. Por fim, são apresentadas as conclusões do presente trabalho.

\section{CONVENÇÃO SOBRE OS DIREITOS DAS PESSOAS COM DEFICIÊNCIA E}

\section{CAPACIDADE LEGAL}

Conforme mencionado, o artigo 12, item 2, da Convenção sobre os Direitos das Pessoas com Deficiência estabelece como dever aos Estados Partes o reconhecimento de que as pessoas com deficiência gozam de capacidade legal em igualdade de condições com as demais pessoas em todos os aspectos da vida. Tem-se a fixação da capacidade legal como um direito humano. Entretanto, a Convenção não definiu o que entende por capacidade legal, apenas trouxe diretrizes do conceito e fixou um modelo de proteção, reservando aos Estados Partes a concretização desse regime. No artigo 12, item 4, está prevista a obrigação dos Estados de assegurarem que todas as medidas relativas ao exercício da capacidade legal respeitem os direitos, a vontade e as preferências da pessoa, sendo proporcionais e adequadas a cada caso concreto.

A capacidade pode ser de direito ou de exercício. A capacidade de direito é comumente definida pela doutrina como a "aptidão oriunda da personalidade, para adquirir os direitos na vida civil". ${ }^{2}$ No ordenamento jurídico brasileiro, sua previsão legal está no art. $1^{\circ}$ do Código Civil, que tem a seguinte redação: “Toda pessoa é capaz de direitos e deveres na ordem civil”. Dessa forma, a capacidade de direito está intrinsecamente ligada à noção de pessoa, bastando que se reconheça a existência de personalidade para que se conclua pela também existência de capacidade de direito. ${ }^{3}$

\footnotetext{
2 PEREIRA, Caio Mário da Silva. Instituições de Direito Civil. Vol. 1. Introdução ao Direito Civil. Teoria Geral de Direito Civil. 30 ed. Rio de Janeiro: Forense, 2017. p. 221.

${ }^{3}$ No direito brasileiro prevalece o posicionamento que não admite qualquer redução na capacidade de direito. Ou seja, a todo ser dotado de personalidade seria também reconhecida a capacidade de direito, a qual não pode sofrer limitação, sob pena de se atentar contra a dignidade da pessoa humana. Nesse sentido, SIMÃO, José Fernando. Responsabilidade Civil do Incapaz. São Paulo: Atlas, 2008. p. 20. De acordo com esse posicionamento, praticamente inexiste distinção entre personalidade e capacidade de direito. Contudo, existem posicionamentos contrários tanto no direito brasileiro (FRANÇA, R. Limongi. Instituições de Direito Civil. São Paulo: Saraiva, 1988. p. 53; EBERLE, Simone. A Capacidade entre o Fato e o Direito. Porto Alegre: Sergio Antonio Fabris, 2006), como no direito estrangeiro (ASCENSÃO, José de Oliveira. Direito Civil. Teoria Geral. Vol. 1. Introdução. As Pessoas. Os Bens. $2^{\mathrm{a}}$ ed. Coimbra: Coimbra Editora, 2000. p. 144; TRABUCCHI, Alberto. Istituzioni di Diritto Civile. $40^{\mathrm{a}}$ ed. Padova: CEDAM, 2009. p. 250). Para essa segunda corrente, a capacidade de direito pode sofrer limitação sempre que o sujeito for excluído de certas relações jurídicas. Por exemplo, a capacidade de direito da pessoa jurídica seria menor
} 
A capacidade de exercício ou de fato, por sua vez, é definida como a "aptidão que o ordenamento jurídico reconhece às pessoas para que, diretamente, sem o intermédio de um representante ou assistente, exerçam os direitos e pratiquem os atos da vida civil". ${ }^{4}$ Nos ordenamentos jurídicos em geral, enquanto a capacidade de direito é atribuída a todas as pessoas indistintamente e perdura por toda a vida, a capacidade de fato pode sofrer restrições legais pontuais. Nesse sentido, em determinadas hipóteses de carência de discernimento, os indivíduos são submetidos a um regime especial que limita a possibilidade concreta de atuação jurídica.

O fundamento central do regime de incapacidade é a proteção do sujeito, ${ }^{5}$ de modo que qualquer restrição na capacidade de agir e na autonomia deve se dar com fins a evitar que a pessoa celebre maus negócios ou tome decisões que não correspondam aos seus reais interesses.

$\mathrm{Na}$ redação original do Código Civil brasileiro de 2002, a capacidade de exercício era suprimida totalmente aos menores de dezesseis anos, aos que, por deficiência mental ou enfermidade, não tivesse o necessário discernimento à prática dos atos da vida civil e àqueles que não pudessem exprimir sua vontade (art. $\left.3^{\circ}\right)$. Ainda, a capacidade de exercício era apenas parcialmente reconhecida em relação aos maiores de dezesseis e menores de dezoito anos, aos ébrios habituais, viciados em tóxicos e deficientes mentais com discernimento reduzido, aos excepcionais sem desenvolvimento mental completo e aos pródigos (art. $4^{\circ}$ ).

A partir desses conceitos, o termo capacidade legal previsto no artigo 12, item 2, da Convenção, poderia ser interpretado como capacidade de direito. Ou seja, toda pessoa com deficiência mental ou intelectual teria igual capacidade de direito em relação às demais pessoas, o que não impediria a possibilidade de cada Estado Parte prever em seus ordenamentos jurídicos restrições legais na capacidade de exercício, exatamente como era a sistemática adotada pelo direito brasileiro.

Ocorre que a Convenção sobre os Direitos das Pessoas com Deficiência estabeleceu, ainda, por meio de seu art. 34, a criação do Comitê sobre os Direitos das Pessoas com Deficiência, que fixou uma interpretação própria do termo capacidade legal. Não há um

que a capacidade da pessoa natural, vez que a primeira não pode titularizar todos os direitos cabíveis à segunda.

${ }^{4}$ MELLO, Marcos Bernardes de. Achegas para uma teoria das capacidades em direito. Revista de Direito Privado. São Paulo. v.1. n.3. p.9-34. jul./set. 2000. p. 19.

${ }^{5}$ STANCIOLI, Brunello; PEREIRA, Fabio Queiroz. Princípios que Regem a Incapacidade e o Estatuto da Pessoa com Deficiência. In: PEREIRA, Fabio Queiroz; MORAIS, Luísa Cristina de Carvalho; LARA, Mariana Alves (Org.). A Teoria das Incapacidades e o Estatuto da Pessoa com Deficiência. Belo Horizonte: D'Plácido, 2016. p. 101-113. 
dispositivo a tratar expressamente das atribuições do referido órgão. No entanto, por meio da leitura do texto convencional, é possível identificar que as suas funções estão centradas no monitoramento da concretização das medidas e diretrizes previstas pela Convenção em cada um de seus países signatários. Nesse sentido, os Estado Parte devem submeter ao Comitê "relatório abrangente sobre as medidas adotadas em cumprimento de suas obrigações estabelecidas" (art. 35). Há previsão de apresentação do referido documento dentro do período de dois anos de entrada em vigor da Convenção, além da necessidade de submissão de relatórios subsequentes, ao menos a cada quatro anos. O Comitê tem por função avaliar cada um dos documentos submetidos, fazendo "sugestões e recomendações gerais que julgar pertinentes" (art. 36).

Outra função do Comitê é resultado do Protocolo Facultativo, do qual o Brasil é também signatário. De acordo com o referido instrumento, deve ser reconhecida "a competência do Comitê sobre os Direitos das Pessoas com Deficiência para receber e considerar comunicações submetidas por pessoas ou grupos de pessoas, ou em nome deles, sujeitos à sua jurisdição, alegando serem vítimas de violação das disposições da Convenção pelo referido Estado Parte”. Observa-se, assim, outra função do Comitê, qual seja a de possibilitar que grupos ou indivíduos apresentem denúncias que envolvam a violação de direitos previstos na Convenção. Trata-se de atuação individualizada, que opera diante de específicas situações violadoras de direitos previstos pelo texto convencional, o que também concretiza a função controle do Comitê.

Como forma de concretizar as suas atribuições correlatas ao monitoramento da implementação do texto convencional, o Comitê revela-se legitimado a fixar "diretrizes para a elaboração de relatórios, sugestões e recomendações gerais” (art. 38). Essa atuação demonstrase necessária para que se tenham adequadas balizas de aplicação da Convenção, subsidiando cada um dos Estados nas tarefas de elaboração dos relatórios periódicos e de consecução dos objetivos estabelecidos pela norma convencional. Assim, parece haver legitimidade do Comitê para a elaboração de documentos que sirvam como guia para os países signatários implementarem as medidas previstas pela Convenção.

No exercício de tal tarefa, em 2014, o Comitê estabeleceu a Orientação Geral n 1 , em que foram apresentados alguns subsídios para a determinação do alcance exato das obrigações dos Estados relativamente ao art. 12 da Convenção. 0 referido dispositivo trata do “reconhecimento igual perante a lei" e dispõe de questões que envolvem personalidade jurídica, capacidade e exercício de direitos. Na introdução da Orientação Geral, em seu ponto 4, afirmase que o documento "reflete uma interpretação do art. 12 que se funda nos princípios gerais da Convenção, expostos no art. 3". 
Da leitura da Observação, é possível constatar que a principal questão analisada centrase no alcance do termo capacidade legal, previsto no dispositivo. 0 art. 12 estabelece que "os Estados Partes reconhecerão que as pessoas com deficiência gozam de capacidade legal em igualdade de condições com as demais pessoas em todos os aspectos da vida". Importa, desse modo, determinar qual o alcance da expressão capacidade legal.

Como já assinalado, na tradição do Direito Civil brasileiro, capacidade jurídica é habitualmente dividida em duas tipologias distintas, quais sejam capacidade de direito ou capacidade de exercício. A adoção de cada uma das tipologias traz consigo diferentes consequências para a internalização da Convenção. A interpretação balizada pela capacidade de direito consagra a possibilidade de titularizar direitos e obrigações, mas não impede que, diante de ausência de discernimento, a pessoa seja representada no exercício de seus direitos. Por outro lado, o reconhecimento como capacidade de fato, impede aprioristicamente que qualquer pessoa com deficiência mental ou intelectual tenha a sua vontade substituída pela manifestação exarada por meio do instituto da representação. Essa última direção parece ter sido a seguida pelo Comitê, ao redigir a Orientação Geral $\mathrm{n}^{\circ} 1$, estabelecendo a necessidade de reconhecimento de capacidade plena a qualquer indivíduo, independentemente de seu discernimento ou mesmo de sua cognição. De acordo com a referida Orientação:

A capacidade legal inclui a capacidade de ser titular de direitos e de atuar no direito. A capacidade legal para ser titular de direitos concede à pessoa a integral proteção de seus direitos pelo ordenamento jurídico. A capacidade legal de atuar no direito reconhece essa pessoa como um agente com poder de realizar transações e criar, modificar ou extinguir relações jurídicas. ${ }^{6}$

Pelo trecho transcrito, verifica-se que o termo capacidade legal apresentado na Convenção deve ser entendido como capacidade jurídica e abarca tanto a capacidade de titularizar direitos e obrigações (capacidade de direito) quanto a capacidade de atuar no direito (capacidade de exercício). Acrescenta-se, ainda, que o texto da orientação é claro no sentido de afastar as hipóteses de substituição na manifestação de vontade, pugnando por uma nova concepção de atuação, que se baseia apenas no apoio na tomada de decisões.

\footnotetext{
${ }^{6}$ No original: "Legal capacity includes the capacity to be both a holder of rights and an actor under the law. Legal capacity to be a holder of rights entitles a person to full protection of his or her rights by the legal system. Legal capacity to act under the law recognizes that person as an agent with the power to engage in transactions and create, modify or end legal relationships". COMMITTEE ON THE RIGHTS OF PERSONS WITH DISABILITIES. General comment nº 1. Geneva: 2014. p. 3.
} 
A referida interpretação é reforçada pelas considerações tecidas pelo Comitê, ao apresentar as Observações Finais sobre o Informe Inicial do Brasil. Ao analisar a concretização do art. 12 da Convenção, o Comitê assim se manifestou:

O Comitê insta ao Estado parte que derrogue todas as disposições legais que perpetuem o sistema de substituição na tomada de decisões. Também recomenda que, em consulta às organizações de pessoas com deficiência e outros provedores de serviços, o Estado parte tome medidas concretas para a troca do sistema de substituição de tomada de decisões por um modelo de apoio na tomada de decisões, baseado na autonomia, na vontade e nas preferências da pessoa com deficiência, em total conformidade com o art. 12 da Convenção. Recomenda, ainda, que as pessoas com deficiência atualmente sob curatela sejam informadas sobre o novo marco legal e que o exercício do direito ao apoio em tomadas de decisão seja garantido em todos os casos. ${ }^{7}$

Numa tentativa de adaptar a Convenção ao direito brasileiro e seguindo as diretrizes apontadas pelo Comitê, a Lei $n^{\circ} 13.146$, de 6 de julho de 2015, conhecida como Estatuto da Pessoa com Deficiência, alterou a redação dos artigos $3^{\circ}$ e $4^{\circ}$ do Código Civil brasileiro de modo a retirar qualquer menção à enfermidade ou à deficiência mental como causas de incapacidade de fato. $^{8}$ Em que pese a alteração empreendida pelo legislador brasileiro não ter atendido integralmente a determinação do Comitê, ${ }^{9}$ haja vista a manutenção da possibilidade de instituir

\footnotetext{
${ }^{7}$ No original: "The Committee urges the State party to withdraw all legal provisions that perpetuate the system of substituted decision-making. It also recommends that, in consultation with organizations of persons with disabilities and other service providers, the State party take tangible steps to replace the system of substituted decision-making with a supported decision-making model that upholds the autonomy, will and preferences of persons with disabilities, in full conformity with article 12 of the Convention. It further recommends that all persons with disabilities currently under guardianship be kept duly informed about the new legal scheme, and that the exercise of the right to supported decisionmaking be guaranteed in all cases". COMMITTEE ON THE RIGHTS OF PERSONS WITH DISABILITIES. Concluding observations on the initial report of Brazil. Geneva: 2015. p. 4.

${ }^{8}$ A nova redação é:

Art. $3^{\circ}$. São absolutamente incapazes de exercer pessoalmente os atos da vida civil os menores de 16 (dezesseis) anos.

Art. $4^{\circ}$ São incapazes, relativamente a certos atos ou à maneira de os exercer:

I - os maiores de dezesseis e menores de dezoito anos;

II - os ébrios habituais e os viciados em tóxico;

III - aqueles que, por causa transitória ou permanente, não puderem exprimir sua vontade;

IV - os pródigos.

Parágrafo único. A capacidade dos indígenas será regulada por legislação especial.

${ }^{9}$ COMITEE DOS DIREITOS DAS PESSOAS COM DEFICIÊNCIA. Observações Conclusivas sobre o Relatório Inicial do Estado Brasileiro. 2015.
} 
a curatela da pessoa com deficiência, o Estatuto fixou a plena capacidade de exercício da pessoa com deficiência mental ou intelectual. ${ }^{10}$

Não há mais no ordenamento jurídico brasileiro nenhuma hipótese de incapacidade específica para as pessoas com falta ou redução do discernimento em virtude de enfermidade ou deficiência mental ou intelectual. Estas, quando não puderem exprimir qualquer vontade, poderão ser consideradas relativamente incapazes com fundamento no art. $4^{\circ}$, III do Código Civil. Porém, existindo a possibilidade de manifestação de qualquer vontade, ainda que não consciente ou autônoma, não se pode considerar o sujeito como incapaz, haja vista o caráter stricto iure do regime de incapacidades, que inadmite interpretações extensivas. ${ }^{11}$

Não obstante a motivação da Convenção e do Estatuto de incluir as pessoas com deficiência na sociedade e afastar qualquer forma de discriminação, impossível ignorar a existência de variadas conjunturas em que deficiências ou enfermidades mentais retiram todo o potencial cognitivo do indivíduo. Em tal contexto, pode-se concluir que dotar esse sujeito de plena capacidade de exercício significaria desprotegê-lo, ${ }^{12}$ uma vez que a sua situação fática não permite o alcance da igualdade material presente no texto da Convenção. A mera atribuição de capacidade pela lei não tem o condão de alterar a realidade fática. Pessoas com ausência de discernimento não estão aptas a agir sozinhas no plano concreto, celebrando atos da vida civil. Estabelecer que elas não podem ser substituídas por um representante nos processos de tomada de decisão pode culminar no abandono dessas pessoas à própria sorte, afastando-se da ideia de proteção, inclusão e igualdade material.

Assim, cabe questionar se a plena capacidade de exercício seria um direito humano, como proclamado na Orientação Geral $n^{\circ} 1$ do Comitê, ou se o melhor caminho teria sido a indicação de um sistema de capacidades que ponderasse individualmente as potências do sujeito, determinando a sua correlata aptidão para o exercício dos variados atos jurídicos de natureza civil.

\footnotetext{
10 Para além das alterações empreendidas nos artigos $3^{\circ}$ e $4^{\circ}$ do Código Civil, o Estatuto da Pessoa com Deficiência prevê expressamente em seu art. $6^{\circ}$ que "a deficiência não afeta a plena capacidade civil da pessoa".

${ }^{11}$ RÁO, Vicente. O Direito e a Vida dos Direitos. 7. ed. Atual. Ovídio Rocha Sampaio Sandoval. São Paulo: Revista dos Tribunais, 2013. p. 630.

12 LARA, Mariana Alves; PEREIRA, Fabio Queiroz. Estatuto da Pessoa com Deficiência: Proteção ou Desproteção? In: PEREIRA, Fabio Queiroz; MORAIS, Luísa Cristina de Carvalho; LARA, Mariana Alves (Org.). A Teoria das Incapacidades e o Estatuto da Pessoa com Deficiência. Belo Horizonte: D'Plácido, 2016, p. $115-152$.
} 


\section{CAPACIDADE DE EXERCÍCIO E DIREITOS HUMANOS}

A capacidade de exercício possui inegável importância para a realização humana. Enquanto representação do "poder de dirigir-se autonomamente na ordem civil", ${ }^{13}$ ela operacionaliza a liberdade individual no mundo jurídico. Metaforicamente, a capacidade de exercício "pode ser vista [...] como a autonomia da vontade com 'vestes' dogmáticas", ${ }^{14}$ na medida em que concretiza juridicamente a autonomia, esta reconhecida como "elemento constitutivo"15 e "necessidade primordial"16 da pessoa. Nesse sentido, justifica-se a tendência contemporânea de analisar a capacidade de exercício para além do âmbito negocial e privatístico. Dentre as várias propostas de superação desta aproximação tradicional, ressalta-se a compreensão a partir da ótica dos direitos humanos. ${ }^{17}$

Nos últimos tempos, a interface entre capacidade de exercício e direitos humanos foi impulsionada pela consideração do tema em tratados internacionais protetivos de grupos vulneráveis. A matéria consta, por exemplo, do art. 15 da Convenção sobre a Eliminação de Todas as Formas de Discriminação contra a Mulher (1979), bem como do art. 30 da Convenção Interamericana sobre a Proteção dos Direitos Humanos dos Idosos (2015). Para o presente estudo, destaca-se, sobretudo, o art. 12 da Convenção sobre os Direitos das Pessoas com Deficiência. Os três dispositivos elencados ilustram a crescente preocupação global com a igualdade no exercício da capacidade civil pelos integrantes dos grupos historicamente discriminados.

Nesse contexto, impõe-se a reflexão sobre o que significa, em termos práticos, o reconhecimento da capacidade de exercício dentre os direitos humanos. Atualmente, os ordenamentos jurídicos enfrentam o complexo desafio de conciliar essa nova visão internacional com os mecanismos já consolidados no âmbito interno. É o caso, por exemplo, da construção

${ }^{13}$ EBERLE, Simone. A capacidade entre o fato e o direito. Porto Alegre: Sergio Antonio Fabris Editor, 2006. p. 137.

14 STANCIOLI, Brunello. Sobre a capacidade de fato da criança e do adolescente: sua gênese e desenvolvimento na família. Revista Brasileira de Direito de Família, ano 1, n. 2, p. 37-42, jul./set. 1999. p. 38.

15 STANCIOLI, Brunello. Renúncia ao exercício de direitos da personalidade: ou como alguém se torna o que quiser. Belo Horizonte: Del Rey, 2010. p. 122.

16 GUSTIN, Miracy Barbosa de Sousa. Das necessidades humanas aos direitos: ensaio de sociologia e filosofia do direito. Belo Horizonte: Del Rey, 2009. p. 225.

17 BARRANCO, María del Carmen; CUENCA, Patricia; RAMIRO, Miguel Ángel. Capacidad jurídica y discapacidad: el artículo 12 de la Convención de Derechos de las Personas con Discapacidad. Anuario Facultad de Derecho, Universidad de Alcalá, v. V, p. 53-80, 2012. Disponível em: <http://dspace.uah.es/dspace/bitstream/handle/10017/13421/capacidad_barranco_AFDUA_2012.pdf?seq uence=1 >. Acesso em: 24 ago. 2017. p. 58. 
dogmática da teoria das incapacidades, que passa por uma revisão crítica ao redor do mundo. Afinal, quais as consequências jurídicas e efetivas da tutela da igualdade no exercício da capacidade civil nos tratados internacionais de direitos humanos? Poder-se-ia responder que essa transição vincula os Estados a abolir toda e qualquer diferenciação em relação à capacidade de exercício de seus cidadãos. A abstração e a generalidade presentes nessa interpretação, entretanto, contrariam o desenvolvimento contemporâneo da proteção dos direitos humanos, marcado pela busca de uma proteção específica e concreta das pessoas. A análise desse problema demanda uma breve digressão sobre as linhas gerais do direito internacional dos direitos humanos.

A percepção dos direitos humanos varia conforme o referencial teórico adotado. Dentre as diversas correntes formadas ao longo do tempo, o presente estudo fundamenta-se na tese da historicidade da natureza dos direitos humanos. Na definição de Flávia Piovesan, "enquanto reinvindicações morais, os direitos humanos são fruto de um espaço simbólico de luta e ação social, na busca por dignidade humana, o que compõe um construído axiológico emancipatório". ${ }^{18}$ Esta será a perspectiva utilizada no desenvolvimento a seguir. ${ }^{19}$

A concepção contemporânea dos direitos humanos remonta ao período pós-guerra. Passadas as atrocidades do início do século XX, fortaleceu-se a convicção de que a proteção da pessoa representa um interesse que extrapola o mero domínio estatal. Com efeito, iniciaram-se as tentativas de obtenção de consenso internacional sobre o estabelecimento de parâmetros protetivos mínimos do ser humano (mínimo ético irredutível). ${ }^{20}$ É nesse cenário que surge a Declaração Universal dos Direitos Humanos (1948), consubstanciando um objetivo ideal comum (standard of achievement) $^{21}$ e enfatizando a universalidade, a indivisibilidade e interdependência dos direitos humanos. ${ }^{22}$ Desde então, a proteção internacional dos direitos

\footnotetext{
18 PIOVESAN, Flávia. Direitos humanos e o direito constitucional. 15. ed. São Paulo: Saraiva, 2015. p. 187-188.

19 Saliente-se, contudo, a advertência de Noberto Bobbio: "O problema fundamental em relação aos direitos do homem, hoje, não é tanto o de justificá-los, mas o de protegê-los. Trata-se de um problema não filosófico, mas político." BOBBIO, Norberto. A era dos direitos. Trad. Carlos Nelson Coutinho. Rio de Janeiro: Elsevier, 2004. p. 16.

${ }^{20}$ PIOVESAN, Flávia. Convenção da ONU sobre os Direitos das Pessoas com Deficiência: inovações, alcance e impacto. In: FERRAZ, Carolina Valença et al. Manual dos direitos da pessoa com deficiência. São Paulo: Saraiva, 2012. p. 33-51. p. 37-39.

${ }^{21}$ CANÇADO TRINDADE, Antônio Augusto. Tratado de direito internacional dos direitos humanos, v. I. 2. ed. Porto Alegre: Sergio Antonio Fabris Editor, 2003. p. 80.

22 PIOVESAN, Flávia. Convenção da ONU sobre os Direitos das Pessoas com Deficiência: inovações, alcance e impacto. In: FERRAZ, Carolina Valença et al. Manual dos direitos da pessoa com deficiência. São Paulo: Saraiva, 2012. p. 33-51. p. 39.
} 
humanos foi generalizada mediante a adoção de sucessivos e múltiplos tratados e instrumentos em nível global e regional. ${ }^{23}$ Este corpus juris em expansão mostrou-se dotado de fundamentos, de princípios e de mecanismos de supervisão próprios, o que levou à configuração de uma nova disciplina da ciência jurídica: o Direito Internacional dos Direitos Humanos. ${ }^{24}$

Flávia Piovesan divide o desenvolvimento contemporâneo da proteção dos direitos em duas fases. ${ }^{25}$ A primeira fase é "caracterizada pela tônica da proteção geral, genérica e abstrata, sob o lema da igualdade formal e da proibição da discriminação". ${ }^{26}$ Esta etapa compreende a Declaração Universal dos Direitos Humanos, bem como o Pacto Internacional dos Direitos Econômicos, Sociais e Culturais e o Pacto Internacional dos Direitos Civis e Políticos, ambos de 1966. A segunda fase, por sua vez, é “marcada pela proteção específica e especial, a partir de tratados que objetivam eliminar todas as formas de discriminação que afetam de forma desproporcional determinados grupos". ${ }^{27}$ Esse último estágio abrange diversos instrumentos internacionais, como a Convenção sobre a Eliminação de todas as Formas de Discriminação contra a Mulher e a Convenção sobre os Direitos das Pessoas com Deficiência.

O percurso evolutivo do sistema internacional de proteção dos direitos humanos evidencia a busca de complementação da igualdade formal (de jure equality) com a noção de igualdade material (de facto equality) ${ }^{28}$. O Comentário Geral $\mathrm{n}^{\circ} 16$ de 2005 do Comitê sobre Direitos Econômicos, Sociais e Culturais, por exemplo, ao tratar da igualdade de gênero em relação ao acesso a direitos, exarou que as "garantias de não discriminação e igualdade em tratados

${ }^{23}$ CANÇADO TRINDADE, Antônio Augusto. Tratado de direito internacional dos direitos humanos, v. I. 2. ed. Porto Alegre: Sergio Antonio Fabris Editor, 2003. p. 80.

${ }^{24}$ CANÇADO TRINDADE, Antônio Augusto. Tratado de direito internacional dos direitos humanos, v. I. 2. ed. Porto Alegre: Sergio Antonio Fabris Editor, 2003. p. 82-83.

${ }^{25} \mathrm{Em}$ sentido semelhante, Norberto Bobbio defende que o desenvolvimento teórico e prático dos direitos do homem, a partir do final da guerra, seguiu duas direções: a da universalização e a da multiplicação. BOBBIO, Norberto. A era dos direitos. Trad. Carlos Nelson Coutinho. Rio de Janeiro: Elsevier, 2004. p. 33. ${ }^{26}$ PIOVESAN, Flávia. Convenção da ONU sobre os Direitos das Pessoas com Deficiência: inovações, alcance e impacto. In: FERRAZ, Carolina Valença et al. Manual dos direitos da pessoa com deficiência. São Paulo: Saraiva, 2012. p. 33-51. p. 43.

27 PIOVESAN, Flávia. Convenção da ONU sobre os Direitos das Pessoas com Deficiência: inovações, alcance e impacto. In: FERRAZ, Carolina Valença et al. Manual dos direitos da pessoa com deficiência. São Paulo: Saraiva, 2012. p. 33-51. p. 43.

${ }^{28} \mathrm{Na}$ definição de igualdade material, a doutrina brasileira recorre frequentemente à lição de Rui Barbosa: "A regra da igualdade não consiste senão em quinhoar desigualmente aos desiguais, na medida em que se desigualam. [...] Tratar com desigualdade a iguais, ou a desiguais com igualdade, seria desigualdade flagrante, e não igualdade”. BARBOSA, Rui. Oração aos moços. 5. ed. Anot. Adriano da Gama Kury. Rio de Janeiro: Casa de Rui Barbosa, 1999. Disponível em: < http://www.casaruibarbosa.gov.br/dados/DOC/artigos/rui_barbosa/FCRB_RuiBarbosa_Oracao_aos_mocos .pdf>. Acesso em: 25 ago. 2017. p. 26. 
internacionais de direitos humanos preveem a igualdade tanto de facto como de jure". ${ }^{29}$ No mesmo sentido, Antônio Augusto Cançado Trindade pontua que o Direito Internacional dos Direitos Humanos "não busca obter um equilíbrio entre as partes, mas remediar os efeitos do desequilíbrio das disparidades na medida em que afetam os direitos humanos". 30

É à luz desse contexto que devem ser compreendidos os tratados internacionais de direitos humanos que estabelecem a igualdade de condições para o exercício da capacidade civil, como a Convenção sobre os Direitos das Pessoas com Deficiência. No campo da capacidade de exercício, portanto, a igualdade deve ser assimilada não apenas formalmente, mas também materialmente. A preservação absoluta e irrestrita da capacidade de exercício pode ser prejudicial àqueles que eventualmente não possuam o necessário discernimento para a prática autônoma de determinados atos da vida civil. Isso não significa, contudo, que os ordenamentos jurídicos possam conter diferenciações arbitrárias e preconceituosas. Diversamente, o reconhecimento da capacidade de exercício no âmbito dos direitos humanos reforça a obrigatoriedade de considerá-la amplamente como regra geral, passível de restrições tão somente pontuais, proporcionais e devidamente fundamentadas. Dessa forma, propugna-se por um sistema casuístico, flexível e submetido a efetivos controles de legitimidade. Essa interpretação da Convenção sobre os Direitos das Pessoas com Deficiência é compartilhada por Glauber Salomão Leite:

A CDPD está pautada na máxima proteção da capacidade da pessoa com deficiência, como forma de resguardar devidamente a sua personalidade. Por isso, eventuais limitações à capacidade de exercício estão condicionadas à promoção da dignidade humana, sendo legítimas apenas na medida em que

\footnotetext{
${ }^{29}$ No original: "7. The enjoyment of human rights on the basis of equality between men and women must be understood comprehensively. Guarantees of non-discrimination and equality in international human rights treaties mandate both de facto and de jure equality. De jure (or formal) equality and de facto (or substantive) equality are different but interconnected concepts. Formal equality assumes that equality is achieved if a law or policy treats men and women in a neutral manner. Substantive equality is concerned, in addition, with the effects of laws, policies and practices and with ensuring that they do not maintain, but rather alleviate, the inherent disadvantage that particular groups experience. 8 . Substantive equality for men and women will not be achieved simply through the enactment of laws or the adoption of policies that are gender-neutral on their face. In implementing Article 3, States parties should take into account that such laws, policies and practice can fail to address or even perpetuate inequality between men and women, because they do not take account of existing economic, social and cultural inequalities, particularly those experienced by women". COMITTEE ON ECONOMIC, SOCIAL AND CULTURAL RIGHTS. General comment $n^{\circ}$. 16. Geneva: 2005. p. 2-3.

${ }^{30}$ CANÇADO TRINDADE, Antônio Augusto. Tratado de direito internacional dos direitos humanos, v. I. 2. ed. Porto Alegre: Sergio Antonio Fabris Editor, 2003. p. 44.
} 
forem instrumentos voltados ao desenvolvimento da pessoa com deficiência, à sua necessária inclusão social. ${ }^{31}$

Nesse ponto, é cabível uma analogia com a teoria alemã dos limites dos limites (Schranken-Schranken). Não obstante as controvérsias doutrinárias, pode-se afirmar, em apertada síntese, que a teoria dos limites dos limites se ocupa da eficácia dos direitos fundamentais enquanto contentores de seu próprio cerceamento legislativo. ${ }^{32}$ Nas palavras de Robert Alexy, "os direitos fundamentais, enquanto tais, são restrições à sua própria restrição e restringibilidade". ${ }^{33}$ Tais limites imanentes decorrem da Constituição e se referem "tanto à necessidade de proteção de um núcleo essencial do direito fundamental quanto à clareza, generalidade e proporcionalidade das restrições impostas". ${ }^{34}$ Embora formulada originalmente na seara dos direitos fundamentais, a lógica da teoria dos limites dos limites pode ser utilizada na resolução do problema da conformação prática da capacidade de exercício no âmbito dos direitos humanos. 0 princípio da igualdade material demanda que os ordenamentos nacionais realizem diferenciações com vistas à proteção das pessoas que eventualmente não possuam o necessário discernimento para a prática de determinados atos da vida civil. A elaboração dessa legislação restritiva, entretanto, é limitada pelo reconhecimento da importância da capacidade de exercício para a realização humana, que agora conta com respaldo internacional.

\section{A ATUAÇÃO DO COMITÊ SOBRE OS DIREITOS DAS PESSOAS COM DEFICIÊNCIA NA INTERPRETAÇÃO DOS TERMOS DA CONVENÇÃO}

Seja na redação de orientações para a elaboração dos relatórios, seja na análise e julgamento desses mesmos relatórios, o posicionamento do Comitê sobre os Direitos das Pessoas com Deficiência demonstra-se alinhado a uma interpretação que entende capacidade legal como

\footnotetext{
${ }^{31}$ LEITE, Glauber Salomão. O regime jurídico da capacidade civil e a pessoa com deficiência. In: FERRAZ, Carolina Valença et al. Manual dos direitos da pessoa com deficiência. São Paulo: Saraiva, 2012. p. 302321. p. 319.

32 Como explica J. J. Gomes Canotilho: "As leis restritivas estão sujeitas a uma série de requisitos restritivos dessas mesmas leis. Por isso se fala aqui das restrições às restrições ou de limites dos limites. Trata-se de estudar ou analisar a $3 .^{\text {a }}$ instância do procedimento da restrição de direitos. Depois de determinado o âmbito de protecção e averiguada a existência de uma autêntica restrição através de lei, cumpre verificar se a lei restritiva preenche os requisitos constitucionais fixados". CANOTILHO, J. J. Gomes. Direito constitucional e teoria da Constituição. 7. ed. Almedina: Coimbra, 2003. p. 451.

${ }_{33}$ ALEXY, Robert. Teoria dos direitos fundamentais. Trad. Virgílio Afonso da Silva. 2. ed. Malheiros: São Paulo, 2015. p 296.

${ }^{34}$ MENDES, Gilmar Ferreira; BRANCO, Paulo Gustavo Gonet. Curso de direito constitucional. 7. ed. São Paulo: Saraiva, 2012. p. 231.
} 
capacidade plena, abarcando não só a possibilidade de titularizar direitos e obrigações, como também de exercer autonomamente os direitos, sem a previsão de decisões tomadas em substituição à vontade da pessoa com deficiência.

A referida baliza hermenêutica acaba por levantar uma série de questionamentos correlatos às hipóteses fáticas em que o deficiente apresenta ausência ou déficit extremamente significativo de cognição ou discernimento. Nessas situações revelam-se insuficientes as soluções trazidas, pois não há como implementar decisão apoiada, quando a parte não demonstra ser capaz de manifestar vontade com qualidade tal a ser tomada em consideração. É importante destacar que não há nenhuma orientação específica relativamente às referidas vivências, o que redunda na materialização de um tratamento formalmente igual ao oferecido à generalidade das pessoas com deficiência.

Diante de tal panorama, parece ser imperiosa uma reflexão sobre os limites para o exercício da tarefa interpretativa pelo Comitê. Além disso, deve ser apurada a adequação das orientações elaboradas, tendo por elementos basilares a necessidade de proteção das pessoas com deficiência mental ou intelectual e a atenção aos diferentes contornos que permeiam o exercício de direitos e obrigações.

As normas internacionais revelam um tratamento específico no que concerne à hermenêutica de seus textos, notadamente pelo fato de alcançarem variados ordenamentos jurídicos. Como assinalado por Francisco Rezek, “interpretar o tratado internacional significa determinar o exato sentido da norma jurídica expressa num texto obscuro, impreciso, contraditório, incompleto ou ambíguo". ${ }^{35}$ Vê-se, pois, que as imprecisões correlatas ao texto convencional podem ser solvidas em consonância com uma interpretação adequada, que é realizada de acordo com normas e construções teóricas que delimitam o seu exercício.

A Convenção de Viena sobre Direito dos Tratados (1969) é um importante instrumento de direito internacional que objetiva harmonizar as práticas procedimentais que envolvam tratados e convenções internacionais. Em seu texto, observa-se uma preocupação com a metodologia do exercício hermenêutico, que ali encontra contornos para a sua correta concretização. Em seu art. 31, a referida Convenção apresenta algumas das principais diretrizes de interpretação dos tratados e convenções internacionais. De acordo com esse dispositivo, "um tratado deve ser interpretado de boa-fé segundo o sentido comum atribuível aos termos do tratado em seu

${ }^{35}$ REZEK, José Francisco. Direito internacional público. 9. ed. São Paulo: Saraiva, 2002. 
contexto e à luz de seu objetivo e finalidade". É de se questionar assim qual seria o sentido comum atribuível ao termo "capacidade legal”, encontrado na Convenção.

Interpretar o termo "capacidade legal” como capacidade de fato não revela coerência ao se contrastar a expressão com o restante do art. 12. Em seu item 3, o dispositivo prevê que "os Estados Partes assegurarão que todas as medidas relativas ao exercício da capacidade legal incluam salvaguardas apropriadas e efetivas para prevenir abusos, em conformidade com o direito internacional dos direitos humanos". Ao utilizar a expressão "exercício da capacidade legal", observa-se que a capacidade legal não pode ser compreendida como capacidade de exercício (ou capacidade de fato), pois haveria uma redundância na referida construção. Além disso, o próprio texto convencional prevê a necessidade de salvaguardas que tenham por objetivo proteger as pessoas com deficiência de abusos e, em complementação, é afirmado que "as salvaguardas serão proporcionais ao grau em que tais medidas afetarem os direitos e interesses da pessoa".

Para além dessa inadequação, a compreensão de capacidade legal como capacidade de exercício revela claramente algumas inconsistências quando se analisa a tradução da Orientação Geral $\mathrm{n}^{\circ} 1$ para línguas de matriz ocidental. A título de exemplo, no item 13 do texto em inglês do documento, verifica-se o seguinte trecho com a definição de capacidade legal: "Legal capacity is the ability to hold rights and duties (legal standing) and to exercise those rights and duties (legal agency)". ${ }^{36} 0$ mesmo trecho é traduzido para o espanhol do seguinte modo: "La capacidad jurídica es la capacidad de ser titular de derechos y obligaciones (capacidad legal) y de ejercer esos derechos y obligaciones (legitimación para actuar)". ${ }^{37}$ Se compararmos as duas construções é possível identificar uma apreensão diversa do que significa "capacidade legal” (capacidad legal) no âmbito da língua espanhola, qual seja a capacidade de ser titular de direitos e obrigações. Verifica-se que o documento traduz "legal capacity" como "capacidade jurídica" e não como "capacidade legal”, expressões que possuem significado diverso no contexto de variados países. ${ }^{38}$

\footnotetext{
${ }^{36}$ COMMITTEE ON THE RIGHTS OF PERSONS WITH DISABILITIES. General comment $\mathrm{n}^{\circ}$ 1. Geneva: 2014. p. 3. 37 COMITÉ SOBRE LOS DERECHOS DE LAS PERSONAS COM DISCAPACIDAD. Observación general $n^{\circ} 1$. Geneva: 2014. p. 4.

${ }^{38}$ No texto em francês, a expressão capacidade legal é também traduzida como capacidade jurídica: "La capacite juridique est la capacité d'avoir des droits et des obligations (statut juridique) et d'exercer ces droits et d'exécuter ces obligations (capacité d'agir en droit)". COMITÉ DES DROITS DES PERSONNES HANDICAPÉES. Observation générale ${ }^{\circ} 1$. Geneva: 2015. p. 4.
} 
Nesse sentido, a referida tradução realizada pelo Comitê corrobora o argumento de que não se dotou a norma do "sentido comum atribuível aos termos do tratado em seu contexto e à luz de seu objetivo e finalidade", conforme orientação dada pelo art. 31 da Convenção de Viena sobre Direito dos Tratados. Se tomado o sentido mais habitual do termo "capacidade legal", concluir-se-ia por interpretá-lo como capacidade de direito e não como capacidade de exercício.

Ainda sobre a base interpretativa apresentada pela Orientação Geral $n^{\circ} 1$, verifica-se a sua não conformação ao denominado princípio da integração. De acordo com lan Brownlie, o referido princípio é corolário do princípio do sentido comum e prevê que o significado deve emergir no contexto do tratado como um todo e sob as luzes de seu objeto e de suas finalidades. $^{39}$ No que concerne aos tratados que envolvam direitos humanos, o caráter teleológico da interpretação é ainda reforçado, tendo em consideração a ideia de proteção intrínseca ao referido campo do Direito. De acordo com Antônio Augusto Cançado Trindade:

[...] a interpretação teleológica, com ênfase na realização do objeto e propósito dos tratados de direitos humanos, tem sido adotada pelos órgãos de supervisão internacional, como o melhor método de assegurar uma proteção eficaz dos direitos humanos. É, efetivamente, o que mais fielmente reflete a natureza especial dos tratados de direitos humanos, e o que tem possibilitado a configuração da "autonomia" dos conceitos nestes últimos consignados. ${ }^{40}$

Como a Convenção sobre os Direitos das Pessoas com Deficiência é reconhecida como norma de direitos humanos, é importante interpretá-la teleologicamente, de modo a propiciar o maior grau de proteção aos indivíduos a quem a norma internacional é direcionada. Nas situações em que uma pessoa com deficiência apresenta severo grau de comprometimento em seu discernimento, dotá-la de capacidade plena, a partir de uma interpretação da expressão “capacidade legal”, significa ampliar a sua esfera de desproteção. Por um lado, o apoio na tomada de decisões no exercício dos direitos subjetivos parece só ser materialmente concebível em hipóteses em que seja identificado algum grau de discernimento, o que pode não se demonstrar em variadas situações concretas. Por outro lado, sustentar uma imperatividade da capacidade plena a todas as pessoas com deficiência, sem a devida atenção às potencialidades e às limitações de cada indivíduo, significa criar um sistema de igualdade formal onde

\footnotetext{
${ }^{39}$ No original: "Another corollary of principle of ordinary meaning is the principle of integration: the meaning must emerge in the context of treaty as whole and in the light of its objects and purposes". BROWNLIE, Ian. Principles of public international Law. 6. ed. Oxford: Oxford University Press, 2003. p. 604.

40 CANÇADO TRINDADE, Antônio Augusto. Tratado de direito internacional dos direitos humanos, v. II. Porto Alegre: Sergio Antonio Fabris Editor, 1999.
} 
substancialmente são encontradas severas diferenças. O regime de incapacidades deve ser pensado justamente enquanto sistema de proteção de indivíduos que não se revelam, no plano material, nas mesmas condições de exercício de direitos que o restante da coletividade.

Por fim, como já assinalado, a interpretação tem que ser realizada tendo por pano de fundo todo o texto convencional, além do contexto em que se deu a concretização do tratado ${ }^{41}$. Uma apropriada reflexão sobre a interpretação do termo “capacidade legal” deve ter em consideração outros dispositivos da norma internacional. Desse modo, observa-se que o item 4 do art. $4^{\circ}$ da Convenção confirma o exposto, ao dispor que "nenhum dispositivo da presente convenção afetará quaisquer disposições mais propícias à realização dos direitos das pessoas com deficiência, as quais possam estar contidas na legislação do Estado Parte ou no direito internacional em vigor para esse Estado". De acordo com Roberto Caldas:

O item 4 incorpora à Convenção um importante princípio de interpretação das normas sobre direitos humanos: o princípio pro personae. A Convenção somente pode ser implementada no sentido de ampliar a proteção às pessoas com deficiência, jamais de modo a restringi-la. Isso significa que as normas internas e internacionais devem interagir. 0 que define qual norma deve ser aplicada, se a interna ou a internacional, não é uma hierarquia formal previamente estabelecida, mas sim a substância da norma, devendo prevalecer aquela que conferir a proteção mais ampla ao ser humano. ${ }^{42}$

Portanto, o aludido princípio pro personae indica a necessidade de se adotar um viés interpretativo que seja mais adequado às necessidades de todas as pessoas com deficiência. A interpretação do termo "capacidade legal" como capacidade de exercício, indicada pelo Comitê, traz consigo problemas correlatos à desproteção de uma série de pessoas que não são dotadas de cognoscibilidade ou discernimento suficientes para atuar no âmbito jurídico. Desse modo, as diretrizes interpretativas apresentadas pela Orientação Geral $n^{\circ} 1$ não se apresentam em consonância com as normas interpretativas de tratados internacionais, além de se revelarem em sentido contrário a todo o sistema de proteção de direitos humanos hoje existente.

\footnotetext{
41 "The context of a treaty for purposes of interpretation comprises, in addition to the treaty, including its preamble and annexes, any agreement or instrument related to the treaty and drawn up in connection with its conclusion." BROWNLIE, lan. Principles of public international Law. 6. ed. Oxford: Oxford University Press, 2003. p. 604.

42 CALDAS, Roberto. Obrigações gerais. Novos comentários à Convenção sobre os Direitos das Pessoas com Deficiência. Org. Joelson Dias, Laíssa da Costa Ferreira, Maria Aparecida Gugel e Waldir Macieira da Costa Filho. 3. ed. Brasília: SNPD e SDH-PR, 2014. p. 51.
} 


\section{CONCLUSÃO}

A Convenção sobre os Direitos das Pessoas com Deficiência traz consigo uma dificuldade de internalização em cada um dos países signatários de questões atinentes à denominada capacidade legal. Como visto, o art. 12 da Convenção estabelece que as pessoas com deficiência gozam de capacidade legal em igualdade de condições com as demais pessoas em todos os aspectos da vida. Nesse contexto, a compreensão de capacidade legal enquanto capacidade de direito ou capacidade de exercício impõe aos Estados Partes diferentes obrigações, tendo em consideração que cada uma das expressões traz consigo um conteúdo diverso.

O Comitê sobre os Direitos das Pessoas com Deficiência estabeleceu, por meio da Orientação Geral n. 1, uma interpretação da capacidade legal como capacidade plena, abarcando a capacidade de titularizar direitos e obrigações (capacidade de direito) e a capacidade de exercer autonomamente esses mesmos direitos e obrigações (capacidade de exercício ou capacidade de fato). A referida compreensão imporia a cada um dos países signatários a abolição de qualquer regime de substituição de vontade e primaria pela consagração apenas de regimes de apoio na tomada de decisões.

Entretanto, a análise do desenvolvimento histórico do Direito Internacional dos Direitos Humanos evidencia o objetivo de alcançar mecanismos de amparo concretos e efetivos. Para além da igualdade formal, busca-se atualmente a igualdade material. Com efeito, é insuficiente uma leitura abstrata e genérica da questão. O reconhecimento da capacidade de exercício dentre os direitos humanos traz problemas de ordem prática, em razão dos diferentes graus de discernimento apresentados dentro do grupo das pessoas com deficiência mental ou intelectual. Assim, reconhecer igualdade de condições nas situações em que há uma diferença substancial significaria fugir ao fim último dos direitos humanos que é a proteção dos indivíduos em atenção às suas vulnerabilidades.

Dessa feita, confirmou-se a hipótese inicial de que a interpretação do Comitê para o termo "capacidade legal", apresentado na Convenção, não se revela adequada, quando contrastada com as normas e princípios internacionais de interpretação dos tratados. 0 sentido adotado não revela ser o mais comum atribuível à expressão e o referido fato resta ainda mais claro, quando analisadas as traduções da Orientação Geral n 1 para o espanhol e para o francês. Além disso, a lógica que permeia o adequado exercício hermenêutico não parece ter sido seguida pelo documento, que ignora outras disposições da Convenção. 
Tratados que envolvam direitos humanos devem ser sempre interpretados teleologicamente, o que significa dizer que deve ser adotado o sentido que mais propicie a proteção das pessoas com deficiência. Dotá-las de plena capacidade pode significar uma ampliação das esferas de vulnerabilidade e desproteção. Logo, interpretação mais adequada revela-se naquela que propicia o tratamento do indivíduo em consonância com as suas potencialidades e limitações, isto é, uma interpretação adstrita às diferenças que permeiam todo o grupo das pessoas com deficiência, não as tratando igualmente diante de situações substancialmente diversas.

No contexto brasileiro, uma adequada compreensão do termo “capacidade legal" previsto no artigo 12 da Convenção pode contribuir para o estabelecimento de medidas jurídicas que promovam a autonomia das pessoas com deficiência, sem, contudo, desprotegê-las nos casos que demandam cuidados excepcionais. O Estatuto da Pessoa com Deficiência, em consonância com a leitura defendida pelo Comitê, parece ter buscado o reconhecimento artificial da plena capacidade de exercício para todo e qualquer agente, independentemente da existência de circunstâncias peculiares que prejudiquem significativamente o discernimento no caso concreto. Cabe ao intérprete, portanto, velar para que a tutela da capacidade de exercício das pessoas com deficiência seja concebida e operacionalizada de maneira razoável, livre de preconceitos culturalmente ultrapassados, mas atenta às desigualdades que inevitavelmente marcam a convivência humana.

\section{REFERÊNCIAS}

ALEXY, Robert. Teoria dos direitos fundamentais. Trad. Virgílio Afonso da Silva. 2. ed. Malheiros: São Paulo, 2015.

ASCENSÃO, José de Oliveira. Direito Civil. Teoria Geral. Vol. 1. Introdução. As Pessoas. Os Bens. $2^{a}$ ed. Coimbra: Coimbra Editora, 2000.

BARRANCO, María del Carmen; CUENCA, Patricia; RAMIRO, Miguel Ángel. Capacidad jurídica y discapacidad: el artículo 12 de la Convención de Derechos de las Personas con Discapacidad. Anuario Facultad de Derecho, Universidad de Alcalá, v. V, p. 53-80, 2012. Disponível em: <http://dspace.uah.es/dspace/bitstream/handle/10017/13421/capacidad_barranco_AFDUA_201 2.pdf?sequence=1>. Acesso em: 24 ago. 2017.

BARBOSA, Rui. Oração aos moços. 5. ed. Anot. Adriano da Gama Kury. Rio de Janeiro: Casa de Rui Barbosa, 1999. Disponível em: <http://www.casaruibarbosa.gov.br/dados/DOC/artigos/rui_barbosa/FCRB_RuiBarbosa_Oracao_ aos_mocos.pdf>. Acesso em: 25 ago. 2017. 
BOBBIO, Norberto. A era dos direitos. Trad. Carlos Nelson Coutinho. Rio de Janeiro: Elsevier, 2004.

BROWNLIE, Ian. Principles of public international Law. 6. ed. Oxford: Oxford University Press, 2003.

CALDAS, Roberto. Obrigações gerais. Novos comentários à Convenção sobre os Direitos das Pessoas com Deficiência. Org. Joelson Dias, Laíssa da Costa Ferreira, Maria Aparecida Gugel e Waldir Macieira da Costa Filho. 3. ed. Brasília: SNPD e SDH-PR, 2014.

CANÇADO TRINDADE, Antônio Augusto. Tratado de direito internacional dos direitos humanos, v. I. 2. ed. Porto Alegre: Sergio Antonio Fabris Editor, 2003.

CANÇADO TRINDADE, Antônio Augusto. Tratado de direito internacional dos direitos humanos, v. II. Porto Alegre: Sergio Antonio Fabris Editor, 1999.

CANOTILHO, J. J. Gomes. Direito constitucional e teoria da Constituição. 7. ed. Almedina: Coimbra, 2003.

COMITÉ DES DROITS DES PERSONNES HANDICAPÉES. Observation générale nº 1. Geneva: 2014.

COMITÉ SOBRE LOS DERECHOS DE LAS PERSONAS COM DISCAPACIDAD. Observación general $\mathbf{n}^{\circ} 1$. Geneva: 2014.

COMITTEE ON ECONOMIC, SOCIAL AND CULTURAL RIGHTS. General comment $\mathbf{n}^{\circ}$ 16. Geneva: 2005.

COMMITTEE ON THE RIGHTS OF PERSONS WITH DISABILITIES. Concluding observations on the initial report of Brazil. Geneva: 2015.

COMMITTEE ON THE RIGHTS OF PERSONS WITH DISABILITIES. General comment $\mathbf{n}^{\circ}$ 1. Geneva: 2014.

EBERLE, Simone. A capacidade entre o fato e o direito. Porto Alegre: Sergio Antonio Fabris Editor, 2006.

FRANÇA, R. Limongi. Instituições de Direito Civil. São Paulo: Saraiva, 1988.

GUSTIN, Miracy Barbosa de Sousa. Das necessidades humanas aos direitos: ensaio de sociologia e filosofia do direito. Belo Horizonte: Del Rey, 2009.

LARA, Mariana Alves; PEREIRA, Fabio Queiroz. Estatuto da Pessoa com Deficiência: Proteção ou Desproteção? In: PEREIRA, Fabio Queiroz; MORAIS, Luísa Cristina de Carvalho; LARA, Mariana Alves (Org.). A Teoria das Incapacidades e o Estatuto da Pessoa com Deficiência. Belo Horizonte: D’Plácido, 2016, p. 115-152.

LEITE, Glauber Salomão. O regime jurídico da capacidade civil e a pessoa com deficiência. In: FERRAZ, Carolina Valença et al. Manual dos direitos da pessoa com deficiência. São Paulo: Saraiva, 2012. p. 302-321. 
MELLO, Marcos Bernardes de. Achegas para uma teoria das capacidades em direito. Revista de Direito Privado. São Paulo. v.1. n.3. p.9-34. jul./set. 2000.

MENDES, Gilmar Ferreira; BRANCO, Paulo Gustavo Gonet. Curso de direito constitucional. 7. ed. São Paulo: Saraiva, 2012.

PEREIRA, Caio Mário da Silva. Instituições de Direito Civil. Vol. 1. Introdução ao Direito Civil. Teoria Geral de Direito Civil. 30. ed. Rio de Janeiro: Forense, 2017.

PIOVESAN, Flávia. Convenção da ONU sobre os Direitos das Pessoas com Deficiência: inovações, alcance e impacto. In: FERRAZ, Carolina Valença et al. Manual dos direitos da pessoa com deficiência. São Paulo: Saraiva, 2012. p. 33-51.

PIOVESAN, Flávia. Direitos humanos e o direito constitucional. 15. ed. São Paulo: Saraiva, 2015.

RÁO, Vicente. O Direito e a Vida dos Direitos. 7. ed. Atual. Ovídio Rocha Sampaio Sandoval. São Paulo: Revista dos Tribunais, 2013.

REZEK, José Francisco. Direito internacional público. 9. ed. São Paulo: Saraiva, 2002.

SIMÃO, José Fernando. Responsabilidade Civil do Incapaz. São Paulo: Atlas, 2008.

STANCIOLI, Brunello. Renúncia ao exercício de direitos da personalidade: ou como alguém se torna o que quiser. Belo Horizonte: Del Rey, 2010.

STANCIOLI, Brunello. Sobre a capacidade de fato da criança e do adolescente: sua gênese e desenvolvimento na família. Revista Brasileira de Direito de Família, ano 1, n. 2, p. 37-42, jul./set. 1999.

STANCIOLI, Brunello; PEREIRA, Fabio Queiroz. Princípios que Regem a Incapacidade e o Estatuto da Pessoa com Deficiência. In: PEREIRA, Fabio Queiroz; MORAIS, Luísa Cristina de Carvalho; LARA, Mariana Alves (Org.). A Teoria das Incapacidades e o Estatuto da Pessoa com Deficiência. Belo Horizonte: D’Plácido, 2016, p. 101-113.

TRABUCCHI, Alberto. Istituzioni di Diritto Civile. 40. ed. Padova: CEDAM, 2009.

\section{COMO FAZER A REFERÊNCIA DO ARTIGO (ABNT):}

PEREIRA, Fabio Queiroz; LARA, Mariana Alves; ANDRADE, Daniel de Pádua. O conceito de capacidade legal na convenção sobre os direitos das pessoas com deficiência. Revista Eletrônica do Curso de Direito da UFSM, Santa Maria, RS, v. 13, n. 3, p. 948-969, dez. 2018. ISSN 1981-3694. Disponível em: <

https: //periodicos.ufsm.br/revistadireito/article/view/31839 >. Acesso em: dia mês. ano. doi: http://dx.doi.org/10.5902/1981369431839. 